\title{
PRODUTIVIDADE DO ARROZ DE TERRAS ALTAS EM FUNÇÃO DO MANEJO DO SOLO E DA ÉPOCA DE APLICAÇÃO DE NITROGÊNIO ${ }^{1}$
}

\author{
Adriano Stephan Nascente ${ }^{2}$, João Kluthcouski², Raimundo Ricardo Rabelo ${ }^{2}$, \\ Priscila de Oliveira ${ }^{3}$, Tarcísio Cobucci ${ }^{2}$, Carlos Alexandre Costa Crusciol ${ }^{4}$
}

\section{ABSTRACT \\ UPLAND RICE YIELD UNDER DIFFERENT \\ SOIL MANAGEMENT SYSTEMS AND NITROGEN APPLICATION TIMES}

Proper soil management and $\mathrm{N}$ application time can significantly increase upland rice yield. Thus, the objective of this study was to evaluate the interaction between soil management and nitrogen application time on upland rice development and yield. The experimental design was randomized blocks, in a 5x2 factorial scheme, consisting of five soil management systems (moldboard plow and leveling disc harrow; harrow plow and leveling disc harrow; "matabroto"-type scarifier; no-tillage; and "Aeromix" - superficial scarification equipment) and two $\mathrm{N}$ application times (all $\mathrm{N}$ in the base, being $45 \mathrm{~kg} \mathrm{ha}^{-1}$ of $\mathrm{N}$ applied with the aid of a mechanical traction fertilizer machine, 1 day before rice sowing, $+45 \mathrm{~kg} \mathrm{ha}^{-1}$ of $\mathrm{N}$ at sowing; and $45 \mathrm{~kg} \mathrm{ha}^{-1}$ of $\mathrm{N}$ at sowing $+45 \mathrm{~kg} \mathrm{ha}^{-1}$ at the beginning of plant tillering), with 4 repetitions. There was no interaction among factors, concerning final plants stand. For treatments where the soil was plowed by using moldboard plow and disk harrow, yield was higher when the nitrogen was parceled out. When nitrogen was all applied during the planting time, the treatment with the "matabroto"-type scarifier presented the highest yield, differing statistically from all the other treatments. Conventional tillage yield (moldboard plow or disk harrow) was similar to no-tillage, when all $\mathrm{N}$ was applied during the planting time.

KEY-WORDS: Oryza sativa; no-tillage; conventional tillage; scarification.

\section{INTRODUÇÃO}

O Sistema Plantio Direto (SPD) ocupou, no País, na safra 2005/2006, área aproximada de 25 milhões de hectares, dos quais cerca de $40 \%$ encontram-se em áreas de Cerrado (Febrapdp 2009). Este sistema traz benefícios ambientais, como a redução

\section{RESUMO}

O manejo adequado do solo e a identificação da época de aplicação de $\mathrm{N}$ podem aumentar, significativamente, a produtividade do arroz de terras altas. Neste contexto, objetivouse, com este trabalho, avaliar a interação do manejo do solo com a época de aplicação de nitrogênio, no desenvolvimento e produtividade da cultura. O delineamento experimental utilizado foi o de blocos ao acaso, em esquema fatorial $5 \times 2$, sendo 5 tipos de manejo do solo (arado de aiveca e grade niveladora; grade aradora e grade niveladora; escarificador tipo "matabroto"; SPD; e "Aeromix" - equipamento de escarificação superficial) e duas épocas de aplicação de nitrogênio (todo N na base, sendo $45 \mathrm{~kg} \mathrm{ha}^{-1}$ de nitrogênio aplicados com adubadora de tração mecânica, 1 dia antes da semeadura do arroz, $+45 \mathrm{~kg} \mathrm{ha}^{-1}$ de nitrogênio aplicados no ato da semeadura; e $45 \mathrm{~kg} \mathrm{ha}^{-1}$ de nitrogênio aplicados no ato da semeadura $+45 \mathrm{~kg} \mathrm{ha}^{-1}$ aplicados no início do perfilhamento das plantas), com 4 repetições. Não houve interação dos fatores, para a variável estande final de plantas. Nos tratamentos onde houve revolvimento de solo com arado de aiveca e grade, observou-se maior produtividade quando o nitrogênio foi parcelado. Quando o nitrogênio foi aplicado todo no plantio, o tratamento com escarificador tipo "matabroto" apresentou a maior produtividade, diferindo de todos os outros tratamentos. O plantio convencional (aiveca ou grade) apresentou produtividade semelhante ao SPD, quando se aplicou o $\mathrm{N}$ todo no plantio.

PALAVRAS-CHAVE: Oryza sativa; plantio direto; plantio convencional; escarificação.

na densidade populacional de plantas daninhas e nas perdas de solo, fertilizantes e pesticidas, reduzindo a poluição das águas superficiais (Fornarolli et al. 1998, Vidal et al. 1998, Wietholther et al. 1998).

Entretanto, pesquisas demonstraram que o cultivo do arroz de terras altas sob SPD apresentou menores rendimentos, quando comparado ao sistema

1. Trabalho recebido em jun./2009 e aceito para publicação em jan./2011 (nº registro: PAT 6509/ DOI 10.5216/pat.v41i1.6509).

2. Embrapa Arroz e Feijão, Departamento Técnico-Científico, Santo Antônio de Goiás, GO, Brasil.

E-mails: adriano@cnpaf.embrapa.br, joaok@cnpaf.embrapa.br, raimundo@cnpaf.embrapa.br, cobucci@cnpaf.embrapa.br.

3. Universidade de São Paulo, Escola Superior de Agricultura "Luiz de Queiroz", Departamento de Fitotecnia, Piracicaba, SP, Brasil.E-mail: poliveira@esalq.usp.br.

4. Universidade Estadual Paulista, Faculdade de Ciências Agronômicas, Departamento de Agricultura, Botucatu, SP, Brasil. E-mail: crusciol@fca.unesp.br. 
convencional (Stone et al. 1980, Seguy \& Bouzinac 1992, Kluthcouski et al. 2000). Isto pode ocorrer em razão da exigência da cultura, em solos com maior macroporosidade ou demanda inicial por nitrogênio, na forma amoniacal, sendo, portanto, muito sensível à qualidade do perfil do solo (Seguy \& Bouzinac 1992, Kluthcouski et al. 2000). Desta forma, observa-se que ainda é necessário o desenvolvimento de pesquisas que viabilizem a produção de arroz de terras altas no SPD, uma vez que a demanda para uso desta cultura, neste sistema, vem crescendo, principalmente em áreas de Cerrado, como opção de rotação (Moura Neto et al. 2002).

Também, no preparo convencional do solo, onde, normalmente, as operações são realizadas continuamente e em mesma profundidade (Pedroso \& Corsini 1983), pode ocorrer a formação de camada compactada conhecida como pé-de-arado ou pé-de-grade, que causa compactação (redução do volume de macroporos) e dificulta o desenvolvimento das raízes do arroz.

Kluthcouski et al. (1988) verificaram que o enraizamento do arroz de terras altas aumentou $26 \%$, no perfil de 0-60 cm, quando o solo foi descompactado à profundidade de até $30 \mathrm{~cm}$. Para Oliveira et al. (1996), o preparo profundo do solo com arado de aiveca minimiza o efeito da deficiência hídrica e proporciona aumentos na produção de grãos. Também para Bastos et al. (2002), o preparo do solo com grades aradora + niveladora e escarificador + niveladora proporcionaram maior produtividade ao arroz de terras altas, em relação ao plantio direto.

$\mathrm{O}$ nitrogênio $(\mathrm{N})$ é o nutriente que mais limita o desenvolvimento, a produtividade e a biomassa da maioria das culturas (Lopes et al. 2004). É um elemento que se perde facilmente por lixiviação, volatilização e desnitrificação no solo. Em decorrência destas perdas, a eficiência de utilização do nutriente pelas plantas é baixa (50-60\%). Tem sido habitual a recomendação do parcelamento da adubação nitrogenada, com o intuito de aumentar sua eficiência. No entanto, a suplementação deste nutriente pode ocorrer tardiamente, neste caso, com a principal função de melhorar o nível protéico e não a produtividade das espécies cultivadas, particularmente as graníferas.

Com a evolução na adoção do Sistema Plantio Direto (SPD) em terras altas, é de se esperar aumento gradativo no teor de matéria orgânica e, consequentemente, da atividade microbiológica dos solos. Isto pode alterar não apenas o ciclo do nitrogênio no solo, tornando-o menos disponível para as plantas, em determinado período, como, também, o fluxo de perdas. Assim, em alguns casos, a antecipação da adubação nitrogenada, em relação às recomendações anteriores, ou, até mesmo, em relação à semeadura da cultura, pode ser mais eficiente, no que se refere a aumento da produtividade das culturas graníferas anuais. Não é de se esperar, por exemplo, que, em solos com baixa fertilidade, excessivamente arenosos e pobres em matéria orgânica, ou em solos mal drenados, a prática da aplicação antecipada produza plenos efeitos na eficácia do nutriente (Kluthcouski et al. 2000). Desta forma, verifica-se que a dinâmica do nitrogênio no solo e a capacidade de assimilação metabólica deste elemento pelas diferentes variedades de arroz parece interferir no desempenho da cultura, nos diferentes sistemas de cultivo, principalmente no SPD (Araújo 2005).

$\mathrm{O}$ arroz absorve nitrogênio durante todo o seu ciclo, porém, existem duas fases fisiológicas críticas: o perfilhamento e o início do primórdio floral. Recomenda-se uma aplicação na base (10-30 $\left.\mathrm{kg} \mathrm{ha}^{-1}\right)$, por ocasião do plantio, e uma aplicação (20-70 $\left.\mathrm{kg} \mathrm{ha}^{-1}\right)$ em cobertura, no perfilhamento das plantas (Embrapa 2009). Entretanto, verificou-se que, em trabalhos realizados em Santo Antônio de Goiás e Santa Helena (GO) e Médio Norte do Mato Grosso e Lagoa da Confusão (TO), houve rendimento maior nos tratamentos em que a adubação nitrogenada foi realizada toda na semeadura (Kluthcouski et al. 2006). Neste contexto, objetivou-se, com este trabalho, avaliar a interação do manejo do solo com a época de aplicação de nitrogênio, no desenvolvimento e produtividade do arroz de terras altas.

\section{MATERIAL E MÉTODOS}

O experimento foi desenvolvido na Fazenda Santa Brígida, no município de Ipameri, região Sul do Estado de Goiás (1743'19' 'S, 4809'36'"W e altitude aproximada de $764 \mathrm{~m}$ ), em área anteriormente sob pastagem de Brachiaria decumbens degradada. O clima foi classificado como Cwa, tropical de altitude, segundo Köppen. O solo utilizado foi classificado como Latossolo Vermelho distrófico típico, com textura argilosa (Embrapa 2006), e apresentou as características químicas e granulométricas detalhadas na Tabela 1.

$\mathrm{O}$ delineamento experimental utilizado foi em blocos ao acaso, em esquema fatorial $5 \times 2$, sendo 5 tipos de manejo do solo (arado de aiveca e grade 
Tabela 1. Caracterização química e granulometria física do solo da área experimental (Ipameri, GO, 2007/ 2008).

\begin{tabular}{|c|c|c|c|c|c|c|c|c|c|c|c|c|c|c|c|}
\hline Fator & $\mathrm{pH}$ & $\mathrm{Ca}$ & $\mathrm{Mg}$ & $\mathrm{Al}$ & $\mathrm{H}+\mathrm{Al}$ & $\mathrm{P}$ & $\mathrm{K}$ & $\mathrm{Cu}$ & $\mathrm{Zn}$ & $\mathrm{Fe}$ & $\mathrm{Mn}$ & M.O. & \multicolumn{3}{|c|}{ Textura $\left(\mathrm{g} \mathrm{kg}^{-1}\right)$} \\
\hline Unidade & água & 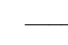 & $-\mathrm{cm}$ & $\mathrm{dm}^{-3}$ & - & & - & $-\mathrm{mg}$ & $n^{-3}$ & & - & $\mathrm{g} \mathrm{dm}^{-3}$ & Argila & Silte & Areia \\
\hline $0-10 \mathrm{~cm}$ & 5,4 & 1,26 & 0,43 & 0,1 & 5,30 & 3,2 & 100 & 2,8 & 5,1 & 40 & 20 & 21 & 569 & 100 & 331 \\
\hline $10-20 \mathrm{~cm}$ & 5,4 & 1,71 & 0,64 & 0,1 & 5,34 & 9,0 & 97 & 3,0 & 6,0 & 41 & 23 & 19 & 569 & 120 & 311 \\
\hline $20-40 \mathrm{~cm}$ & 5,5 & 1,08 & 0,46 & 0,1 & 4,80 & 2,1 & 87 & 2,9 & 3,2 & 38 & 18 & 17 & 589 & 120 & 291 \\
\hline
\end{tabular}

niveladora; grade aradora e grade niveladora; escarificador tipo "matabroto"; SPD; e "Aeromix" - equipamento de escarificação superficial) e duas épocas de aplicação de nitrogênio, na forma de ureia (todo $\mathrm{N}$ na base, sendo $45 \mathrm{~kg} \mathrm{ha}^{-1}$ de nitrogênio aplicados com adubadora de tração mecânica, 1 dia antes da semeadura do arroz, $+45 \mathrm{~kg} \mathrm{ha}^{-1}$ de nitrogênio aplicados no ato da semeadura; e $45 \mathrm{~kg} \mathrm{ha}^{-1}$ de nitrogênio aplicados no ato da semeadura $+45 \mathrm{~kg} \mathrm{ha}^{-1}$ aplicados no início do perfilhamento das plantas), com 4 repetições.

As parcelas experimentais foram compostas por sete linhas de arroz, com 7,35 $\mathrm{m}$ de comprimento, sendo a parcela útil composta pelas duas linhas centrais, descartando-se $50 \mathrm{~cm}$ de cada extremidade.

Avaliou-se o estande final de plantas, altura de plantas e produtividade. A determinação da umidade e a pesagem foram realizadas em sequência e o peso final foi corrigido para $13 \%$ de umidade.

A cultivar utilizada foi a BRS Primavera, indicada para plantio em áreas de abertura e áreas velhas, pouco ou moderadamente férteis, devido à sua tendência ao acamamento, em condições de alta fertilidade. Pode, também, ser plantada em solos férteis, utilizando-se fertilizantes com moderação. Tem apresentado bons resultados, em diversas situações, tais como sistema barreirão (plantio consorciado com pastagem), plantio direto em área de soja e, até mesmo, em safrinha. É considerada uma cultivar de arquitetura moderna (folhas eretas), com grãos longos e finos, com ciclo de 112 dias, precoce (Fonseca et al. 2004, Embrapa 2009).
A semeadura foi realizada no dia 09/11/2007, na densidade de 80 sementes $\mathrm{m}^{-1}$, no espaçamento de $0,35 \mathrm{~m}$, utilizando-se $350 \mathrm{~kg} \mathrm{ha}^{-1}$ do adubo 05 25-15. As sementes foram tratadas com o inseticida Furazin (Carbendazin), na dosagem de 2 litros por $100 \mathrm{~kg}$ de sementes. A semeadura foi realizada com a semeadora Semeato, modelo SHMA.

Avaliou-se o estande final de plantas, altura de plantas e produtividade. A determinação da umidade e a pesagem foram realizadas em sequência e o peso final foi corrigido para $13 \%$ de umidade. As operações de ceifa, trilha e limpeza dos grãos foram realizadas manualmente. Com os dados obtidos, foram realizadas análises de variância e teste comparativo de médias Tukey, a 5\%.

\section{RESULTADOS E DISCUSSÃO}

De acordo com os resultados, foi possível observar que não houve interação entre os fatores tipos de manejo do solo e época de aplicação de nitrogênio, no estande final de plantas (Tabela 2). Esta característica, normalmente, é influenciada pela qualidade da semente.

Com relação à altura final das plantas, verificou-se que não houve efeito para época de aplicação de nitrogênio (Tabela 3). Para o sistema de manejo do solo, o tratamento com grade e aplicacão de nitrogênio todo na base propiciou a maior altura, embora, não diferindo do tratamento com escarificador tipo "matabroto" (Tabela 3). Quando a adubação nitrogenada foi parcelada, a maior altura foi

Tabela 2. Efeito do método de manejo do solo e época de aplicação de nitrogênio no estande final de plantas de arroz de terras altas, cultivar BRS Primavera (Ipameri, GO, 2007/ 2008).

\begin{tabular}{|c|c|c|c|c|c|}
\hline \multirow{2}{*}{ Época de aplicação de nitrogênio } & Aiveca & Grade & Matabroto & SPD & Aeromix \\
\hline & \multicolumn{5}{|c|}{$\left(\mathrm{n}^{\circ}\right.$ de plantas $)$} \\
\hline $\mathrm{N}$ todo na base & $94 \mathrm{~A}^{1} \mathrm{a}$ & $86 \mathrm{~A} \mathrm{a}$ & $100 \mathrm{~A} \mathrm{a}$ & $83 \mathrm{~A} \mathrm{a}$ & $84 \mathrm{~A} \mathrm{a}$ \\
\hline $\mathrm{N}$ base $+\mathrm{N}$ cobertura & $98 \mathrm{~A} \mathrm{a}$ & $105 \mathrm{~A} \mathrm{a}$ & $103 \mathrm{~A} \mathrm{a}$ & $84 \mathrm{~A} \mathrm{a}$ & $102 \mathrm{~A} \mathrm{a}$ \\
\hline C.V. & \multicolumn{5}{|c|}{16,35} \\
\hline
\end{tabular}

${ }^{1}$ Médias seguidas da mesma letra maiúscula, na linha, e minúscula, na coluna, não diferem entre si, pelo teste Tukey, a 5\%. 
Tabela 3. Efeito da interação do método de manejo do solo com a época de aplicação de nitrogênio, na altura final das plantas de arroz de terras altas, cultivar BRS Primavera (Ipameri, GO, 2007/ 2008).

\begin{tabular}{|c|c|c|c|c|c|}
\hline \multirow{2}{*}{ Época de aplicação de nitrogênio } & Aiveca & Grade & Matabroto & SPD & Aeromix \\
\hline & \multicolumn{5}{|c|}{$\mathrm{cm}$} \\
\hline $\mathrm{N}$ todo na base & $108 \mathrm{Ba}^{1}$ & $122 \mathrm{Aa}$ & $113 \mathrm{ABa}$ & $112 \mathrm{Ba}$ & $109 \mathrm{Ba}$ \\
\hline $\mathrm{N}$ base $+\mathrm{N}$ cobertura & $114 \mathrm{ABa}$ & $117 \mathrm{Aa}$ & $108 \mathrm{BCa}$ & $119 \mathrm{Aa}$ & $104 \mathrm{Ca}$ \\
\hline C.V. & \multicolumn{5}{|c|}{4,34} \\
\hline
\end{tabular}

${ }^{1}$ Médias seguidas da mesma letra maiúscula, na linha, e minúscula, na coluna, não diferem entre si, pelo teste Tukey, a $5 \%$.

observada no tratamento com SPD, que não diferiu, significativamente, daqueles com grade e arado de aiveca (Tabela 3 ).

O fato de o manejo do solo em SPD ter propiciado resultado semelhante ao de outros manejos que mobilizaram o solo, na característica altura de plantas (Tabela 3), ocorreu, possivelmente, porque, no plantio direto, utilizou-se uma haste escarificadora ("botinha"), que pode ter favorecido o enraizamento da cultura, resultando em plantas mais altas. Entretanto, se houver camada compactada abaixo de $10 \mathrm{~cm}$, este procedimento pode não ser suficiente, uma vez que o implemento atua somente à profundidade de 0-10 cm. Segundo Guimarães et al. (2001 e 2006), o uso de semeadoras com dispositivos para romper as camadas compactadas no SPD tem apresentado resultados positivos na indução do aprofundamento do sistema radicular do arroz de terras altas, constituindo-se em ferramenta importante para o estabelecimento da cultura no SPD. Resultados semelhantes foram encontrados por Nakayama et al. (2006), que observaram maior altura de plantas nos tratamentos com escarificador.

Para a variável produtividade, verifica-se que, no tratamento onde houve revolvimento de solo com arado de aiveca, a produtividade foi maior quando o nitrogênio foi parcelado, embora não tenha diferido, estatisticamente, do tratamento com grade e escarificador tipo "matabroto" (Tabela 4), e, quando o nitrogênio foi aplicado todo no plantio, o tratamento com escarificador tipo "matabroto" apresentou a maior produtividade, diferindo, estatisticamente, de todos os outros tratamentos (Tabela 4). Isto pode ter ocorrido, provavelmente, devido a um maior crescimento radicular em profundidade, melhorando o aproveitamento de água e nutrientes, em relação aos outros sistemas, além da redução nas perdas de nitrogênio imobilizado pela microbiota, uma vez que não houve revolvimento do solo (Kluthcouski et al. 2006). Resultado semelhante foi obtido por Arf et al. (2001), que obtiveram, no preparo realizado com arado de aiveca e escarificador, produtividade 19\% superior à do preparo realizado com grade aradora, e por Nakayama et al. (2006), que obtiveram maior produtividade do arroz no tratamento com escarificador, em comparação com o SPD e o plantio convencional (PC).

O manejo do solo com arado de aiveca favorece o crescimento do sistema radicular em profundidade, visto que mobiliza maior camada do solo. Entretanto, a produtividade deste sistema foi menor e diferiu, estatisticamente, do sistema de manejo com "matabroto" (Tabela 4). Segundo Kluthcouski et al. (2006), quando se aplica o nitrogênio todo na base e realiza-se o revolvimento do solo (arado de aiveca), a microbiota imobiliza o nitrogênio, não colocando-o à disposição da cultura. Nestes casos, o recomendado é parcelar a adubação nitrogenada, para reduzir a imobilização. Com este procedimento, obteve-se produtividade de $2.329 \mathrm{~kg} \mathrm{ha}^{-1}$, que não

Tabela 4. Efeito do método de manejo do solo e da época de aplicação de nitrogênio na produtividade do arroz de terras altas, cultivar BRS Primavera (Ipameri, GO, 2007/ 2008).

\begin{tabular}{lccccc}
\hline \multirow{2}{*}{ Época de aplicação de nitrogênio } & Aiveca & Grade & Matabroto & SPD & Aeromix \\
\cline { 2 - 6 } & \multicolumn{7}{c}{$\mathrm{kg} \mathrm{ha}^{-1}$} & $2.330 \mathrm{Aa}$ & $1.798 \mathrm{Ba}$ & $1.451 \mathrm{Ba}$ \\
\hline N todo na base & $1.771 \mathrm{Bb}^{1}$ & $1.728 \mathrm{Ba}$ & $1.988 \mathrm{ABa}$ & $1.487 \mathrm{BCa}$ & $1.147 \mathrm{Ca}$ \\
N base + N cobertura & $2.329 \mathrm{Aa}$ & $1.847 \mathrm{ABa}$ & \multicolumn{5}{c}{16,26} \\
\hline C.V. & \multicolumn{5}{c}{} \\
\hline
\end{tabular}

${ }^{1}$ Médias seguidas da mesma letra maiúscula, na linha, e minúscula, na coluna, não diferem entre si, pelo teste Tukey, a 5\%. 
diferiu, estatisticamente, daquela obtida com o uso do "matabroto" e da grade (Tabela 4).

Vale, ainda, ressaltar que o plantio convencional (aiveca ou grade) apresentou produtividade semelhante ao SPD, quando aplicou-se o $\mathrm{N}$ todo no plantio. Este resultado é semelhante ao encontrado por Moura Neto et al. (2002), que avaliaram o desempenho de diversas cultivares de arroz de terras altas, em sistema de PC e SPD, em dois anos consecutivos, e verificaram que o SPD proporcionou rendimento de grãos equivalente ao do PC. Isto evidencia que a aplicação de nitrogênio todo no plantio pode favorecer o estabelecimento do arroz de terras altas no SPD. Entretanto, é preciso esclarecer em quais condições este manejo da adubação se aplica. Guimarães et al. (2006), por exemplo, observaram que existe grande influência do local de cultivo sobre o desempenho do arroz de terras altas.

\section{CONCLUSÕES}

1. Os tratamentos com revolvimento de solo (arado de aiveca e grade) propiciaram maior produtividade à cultura do arroz de terras altas, quando o nitrogênio foi parcelado.

2. Quando o nitrogênio foi aplicado todo no plantio, o tratamento com escarificador tipo "matabroto" apresentou a maior produtividade.

3. O plantio convencional (aiveca ou grade) apresentou produtividade semelhante à do SPD, quando aplicou-se o $\mathrm{N}$ todo no plantio.

\section{REFERÊNCIAS}

ARAÚJO, J. L. Atividade da redutase do nitrato sobre o crescimento e produção de grãos de arroz. $2005.76 \mathrm{f}$. Dissertação (Mestrado em Solos e Nutrição de Plantas)Universidade Federal de Lavras, Lavras, 2005.

ARF, O. et al. Resposta de cultivares de arroz de sequeiro ao preparo do solo e à irrigação por aspersão. Pesquisa Agropecuária Brasileira, Brasília, DF, v. 36, n. 6, p. 871879, jun. 2001.

BASTOS, J. C. H. A. G. et al. Preparo do solo, plantio direto e época de aplicação de nitrogênio no desenvolvimento e produção do arroz de terras altas. In: CONGRESSO DA CADEIA PRODUTIVA DO ARROZ, 1.; REUNIÃO NACIONAL DE PESQUISA DE ARROZ, 7., 2002, Florianópolis. Anais... Santo Antônio de Goiás: Embrapa Arroz e Feijão, 2002. p. 394-397.
EMPRESA BRASILEIRA DE PESQUISA AGROPECUÁRIA (Embrapa). Informações técnicas sobre o arroz de terras altas: Estados de Mato Grosso e Rondônia - safras 2009/2010 e 2010/2011. Santo Antônio de Goiás: Embrapa Arroz e Feijão, 2009. (Documentos, 247).

EMPRESA BRASILEIRA DE PESQUISA AGROPECUÁRIA (Embrapa). Sistema brasileiro de classificação de solos. Rio de Janeiro: Embrapa Solos, 2006.

FEDERAÇÃO BRASILEIRA DE PLANTIO DIRETO NA PALHA (Febrapdp). Evolução da área cultivada no sistema de plantio direto na palha - Brasil. 2009. Disponível em: <http://www.febrapdp.org.br/arquivos/ EvolucaoAreaPDBr72A06.pdf>. Acesso em: 25 jun. 2009.

FONSECA, J. R. et al. Recomendações de cultivares de arroz de terras altas para o Estado do Tocantins. Santo Antônio de Goiás: Embrapa Arroz e Feijão, 2004. (Circular técnica, 66).

FORNAROLLI, D. A. et al. Influência da cobertura morta no comportamento do herbicida Atrazine. Planta Daninha, Botucatu, v. 16, n. 2, p. 97-107, 1998.

GUIMARÃES, C. et al. Arroz de terras altas: espaçamento e densidade de semeadura. Santo Antônio de Goiás: Embrapa Arroz e Feijão, 2001. (Circular técnica, 61).

GUIMARÃES, C. M.; STONE, L. F.; CASTRO, E. da M. de. Comportamento de cultivares de arroz de terras altas no sistema plantio direto em duas profundidades de adubação. BioScience Journal, Uberlândia, v. 22, n. 1, p. 53-59, jan./abr. 2006.

KLUTHCOUSKI, J.; BOUZINAC, S.; SEGUY, L. Preparo do solo. In: ZIMMERMANN, M. J.; ROCHA, M.; YAMADA, T. (Eds.). Cultura do feijoeiro: fatores que afetam a produtividade. Piracicaba: Associação Brasileira para Pesquisa da Potassa e do Fosfato, 1988. p. 249-259.

KLUTHCOUSKI, J. et al. Manejo do solo e o rendimento de soja, milho, feijão e arroz em plantio direto. Scientia Agricola, Piracicaba, v. 57, n. 1, p. 97-104, jan./mar. 2000.

KLUTHCOUSKI, J. et al. Manejo antecipado de nitrogênio nas principais culturas anuais. Informações Agronômicas, Piracicaba, n. 113, p. 1-24, mar. 2006. Encarte técnico.

LOPES, A. S. et al. Sistema plantio direto: bases para o manejo da fertilidade do solo. São Paulo: Associação Nacional para Difusão de Adubos, 2004.

MOURA NETO, F. R.; SOARES, A. A.; AIDAR, H. Desempenho de cultivares de arroz de terras altas sob plantio direto e convencional. Ciência e Agrotecnologia, Lavras, v. 26, n. 5, p. 904-910, set./out. 2002.

NAKAYAMA, F. T. et al. Preparo do solo, manejo de água e nitrogênio em cobertura no arroz de terras altas. 
2006. Disponível em: $<$ http://www.aptaregional.sp.gov. br/artigo.php?id_artigo=321>. Acesso em: 25 jun. 2009.

OLIVEIRA, I. P. et al. Sistema barreirão: recuperação/ renovação de pastagens degradadas em consórcio com culturas anuais. Goiânia: Embrapa-CNPAF, 1996. (Documentos, 64).

PEDROSO, P. A. C.; CORSINI, P. C. Manejo físico do solo. In: FERREIRA, M. E.; YAMADA, T.; MALAVOLTA, E. (Eds.). Cultura do arroz de sequeiro: fatores afetando a produtividade. Piracicaba: Associação Brasileira para a Pesquisa da Potassa e do Fosfato, 1983. p. 225-238.

SEGUY, L.; BOUZINAC, S. Arroz de sequeiro na Fazenda Progresso: $4550 \mathrm{~kg} / \mathrm{ha}$. Informações Agronômicas, Piracicaba, n. 58, p. 1-3, jun. 1992.
STONE, L. F.; SANTOS, A. B. dos; STEINMETZ, S. Influência de práticas culturais na capacidade de retenção de água do solo e no rendimento do arroz-de-sequeiro. Pesquisa Agropecuária Brasileira, Brasília, DF, v. 15, n. 1, p. 63-68, 1980.

VIDAL, R. A. et al. Palha no sistema de semeadura direta reduz a infestação de gramíneas anuais e aumenta a produtividade da soja. Ciência Rural, Santa Maria, v. 28, n. 3, p. 373-377, jul./set. 1998.

WIETHOLTER, S. et al. Fósforo e potássio no solo no sistema plantio direto. In: NUERNBERG, N. J. (Ed.). Conceitos e fundamentos do sistema plantio direto. Lages: Sociedade Brasileira de Ciência do Solo, 1998. p. 121-149. 